\title{
Lentiviral transgenesis of the leopard gecko, Eublepharis macularius
}

\author{
Kaitlyn Hull ${ }^{1}$, Dee Hodgson ${ }^{1}$, Bob Clark ${ }^{2}$, Timothy W. Hickok², James N. Petitte ${ }^{1}$ and \\ Paul E. Mozdziak ${ }^{1^{*}}$ \\ ${ }^{1}$ Department of Poultry Science, North Carolina State University, Raleigh NC, 27695, United States. \\ ${ }^{2}$ Nucleic Sciences LLC. 6701 W. $121^{\text {st }}$ Suite 200, Overland Park KS 66209, United States.
}

Accepted 13 January, 2014

\begin{abstract}
Lentiviral vectors are an effective method of introducing transgenes into the genome of early stage embryos because they transduce both dividing and non-dividing cells. Lentiviral pseudoparticles containing the coding sequence for the fluorescent protein DsRed were injected into freshly laid leopard gecko eggs. Tissue samples were collected from hatchlings, and the samples were tested for the presence of the transgene. Of the injected gecko population, greater than $89 \%$ of efficiency of transgenesis was confirmed using polymerase chain reaction (PCR). Histological evaluations revealed the presence of DsRed 2 in injected gecko organs; with protein production concentrated in the muscle, kidney, and heart. Therefore, lentiviral vectors appear to be viable technology to create transgenic geckos.
\end{abstract}

Key words: DsRed, Eublepharis macularius, Feline Immunodeficienty Virus (FIV), lentiviral transgenesis, reptiles.

\section{INTRODUCTION}

Lentiviruses are used in biotechnology to integrate foreign DNA into a host genome, facilitating foreign gene expression (Pfeifer, 2004). Lentiviruses belong to the family of retroviruses, but unlike most retroviruses, they transduce both dividing and non-dividing cells in vivo (Cockrell and Kafri, 2007). Some of the first lentiviral vectors used for transgenesis were products of the Human Immunodeficiency Virus (HIV) family, consisting of three vectors coding for viral particle generation (Pfeifer, 2004; Nakagawa and Hoogenraad, 2011). Development of Feline Immunodeficienty Virus (FIV) based lentiviral vectors began partly because FIV does not cause human infection since it is a virus that attacks the immune system of cats. FIV based vectors have been used to transduce nondividing and dividing cells of the brain, eye, airway, hematopoietic system, liver, muscle, and pancreas (Wang et al., 1999; Loewen et al., 2001; Curran and Nolan, 2002; Curran et al., 2002; Derksen et al., 2002; Price et al., 2002; Stein and Davidson 2002).

Fluorescent proteins (FPs) occur naturally in organisms of four phyla (Cnidaria, Ctenophora, Arthropoda, and Chordata) including jellyfish, crustaceans, comb jellies, and chordates (Shagin et al., 2004; Deheyn et al., 2007; Haddock and Case, 1999; Chudakov et al., 2010). DsRed, a $28-\mathrm{kDa}$ red homologue of the fluorescent protein GFP, was isolated from the Discosoma species of coral (Matz et al., 1999). The DsRed fluorescent protein has a $583 \mathrm{~nm}$ emission wavelength within the visual spectrum (Sakaue-Sawano et al., 2008; Strack et al., 2010). Since a fluorescence light source is not required to observe DS Red, it is the best candidate fluorochrome for generating transgenic reptiles. 
Transgenic reptiles can be useful tools for a variety of applications. Similar to transgenic fluorescent frogs (Fini et al., 2009), and fish (Gong et al., 2001) fluorescent transgenic reptiles can be used to test toxic, teratogenic, and/or oncogenic agents. Transgenic reptiles could also potentially be used as indicators of pollution (Carvan et al., 2000; Gong and Wan, 2001). Reptiles are utilized as test subjects for the identification of reptile repellents. Fluorescent transgenic reptiles can be useful when an experimental repellant is sprayed directly onto the reptile, and the behavior of a fluorescent reptile can be more easily monitored than a wild-type snake. Lastly, the gecko embryo is amiable to manipulation in much the same way that the chick embryo is amiable for manipulation (Borwornpinyo et al., 2005) making it possible to inject cells from the transgenic geckos into wild-type geckos to analyze cell fate and plasticity in the embryonic environment.

The objective of this study was to achieve lentiviral mediated Eublepharis macularius transgenesis. Leopard geckos are produced in large numbers because they are easy to manage in captivity (Thorogood and Whimster, 1979; Wise, 1997; de Vosjoli et al., 2005; Wise et al., 2009). Because of the leopard gecko's popularity, captive bred lines are available negating the need to obtain wild caught individuals. Captive bred lines of leopard geckos also demonstrate a range of morphological differences including pattern variations such as jungle, striped, patternless, and color variations such as tangerine, white, lavender, melanistic, amelanistic, and leucistic (de Vosjoli et al., 2005). In previous studies, leopard geckos have been used as models for reproductive physiology, central nervous system development, tissue regeneration, and studies of gene expression (Whimster, 1978; Bull, 1987; Valleley et al., 2001). Leopard geckos were chosen as the species for transgenesis because of their general hardiness, captive bred genetic lines, and lastly because their eggs are soft shelled and measure $25 \times 12 \mathrm{~mm}$ on average making them attractive for injection of lentiviral particles into the embryos.

\section{MATERIALS AND METHODS}

\section{Lentivirus production}

The lentiviral vector chosen for transgenesis was pCDF1 from System Biosciences (Mountain View CA): a derivative of Feline Immunodeficiency Virus (FIV) requiring packaging plasmids for viral production. The gene isolated for transgenesis was DsRed 2 from the plasmid pCAG-DsRed (Addgene, Cambridge MA), driven by the chicken beta actin promoter with a cytomegalovirus (CMV) enhancer. A replication defective lentivirus was generated using system biosciences PEG-it kit (Mountain View, CA). The CAGDsRed construct was ligated into pCDF1, a lentiviral vector derived from FIV (Figure 1). Subsequently, the plasmid was transfected into HEK 293 cells. Viral pseudo-particles were collected, frozen, and
Ftitered using NIH 3T3 cells. Cultures exhibited titers averaging $1.6 \times 10^{6} \mathrm{TU} / \mathrm{mL}$.

\section{Gecko egg injection}

Gecko eggs were supplied by the Gourmet Rodent INC. (Jonesville, $\mathrm{FL}$ ). All procedures involving animal were approved by the NC State Institutional Animal Care and Use Committee. Geckos were killed for sampling by an overdose of sodium pentobarbital.

Injection procedures were based upon methods developed for snake embryos (Mozdziak and Petitte, 2010). Gecko embryos at stage 29 of development (Wise et al., 2009) were illuminated under white light to ensure fertility and correct oviposition. Specifically, fiber optic lighting was applied to each end of a gecko egg to illuminate the embryo and associated vasculature. The egg was rotated until the embryo was visible. Subsequently, lentiviral particles were applied to gecko embryos by inserting a 27-gauge needle below the blood ring of the developing embryo and injecting $\sim 200 \mu \mathrm{l}$ of lentiviral supernatant containing $100 \mu \mathrm{g} / \mathrm{mL}$ polybrene directly into the embryo. Care was taken to ensure that the viral supernatant covered the entire embryo. Upon removal of the needle, liquid cement was immediately applied to seal the hole. Eggs were incubated in soaked Perlite (The Scotts Company, Marysville, $\mathrm{OH}$ ) at temperatures between $27-31^{\circ} \mathrm{C}$. Control (CNTL) and injected (INJ) eggs hatched after approximately 30 days of incubation. To ensure that helper retrovirus was not present in the INJ embryos, INJ geckos were macerated and applied to NIH 3T3 cultures in the presence of polybrene, which were observed 2 days later. No positive cells were observed.

\section{Gecko observation}

Immediately after hatching, geckos were observed using a Night Sea DFP-1 Dual Fluorescent Protein flashlight (Bedford, Ma). Pictures of the INJ geckos were taken using a Canon Rebel digital camera (Pleasant Prairie, WI).

\section{Polymerase chain reaction}

\section{DNA extraction materials}

DNA was isolated from 9 INJ geckos and 5 CNTL geckos. Bodies were divided in half; the caudal half, from below the liver to the tail, was digested using the QIAGEN DNA Easy kit (Valencia CA) and analyzed using PCR, the dorsal half was preserved for histological evaluations. Samples were macerated, cells were lysed, and DNA was extracted. DNA concentrations were evaluated by measuring absorbance at $260 \mathrm{~nm}$, and the purity of the DNA was evaluated using the 260/280 ratio. Absorbance was measured using a Thermo Scienific nanodrop (Wilmington, DE). PCR was performed on the 9 gecko DNA samples to evaluate presence of DsRed 2 DNA in the samples. Primer sequences are listed below: 711F: CTG- GGC-AAC-GTG-CTG-GTT-ATT-GTG; 711R: CGT-TGTGGG-AGG-TGA-TGT-CCA-GCT; 169F: TAC-GGC-TCC-AGGGTG-TAC-GTG-AA; 169R: TCA-CCT-TGT-AGA-TGA-AGC-AGCCGT

PCR reactions were executed using PROMEGA GoTaq Green Master Mix (Madison, WI). $10 \mu \mathrm{M}$ forward and reverse primers, and $1 \mu \mathrm{g}$ sample DNA and an annealing temperature of $62-65^{\circ} \mathrm{C}$ was used for all primers. Appropriate temperatures were achieved using a Bio-Rad MJ research Peltier Thermal Cycler 200 (Ramsey, Minnesota). DNA samples were amplified using primers that were expected to generate a $711 \mathrm{bp}$ fragment of the DsRed 2 gene. PCR reactions were fractionated through a $1 \%$ agarose gel for 

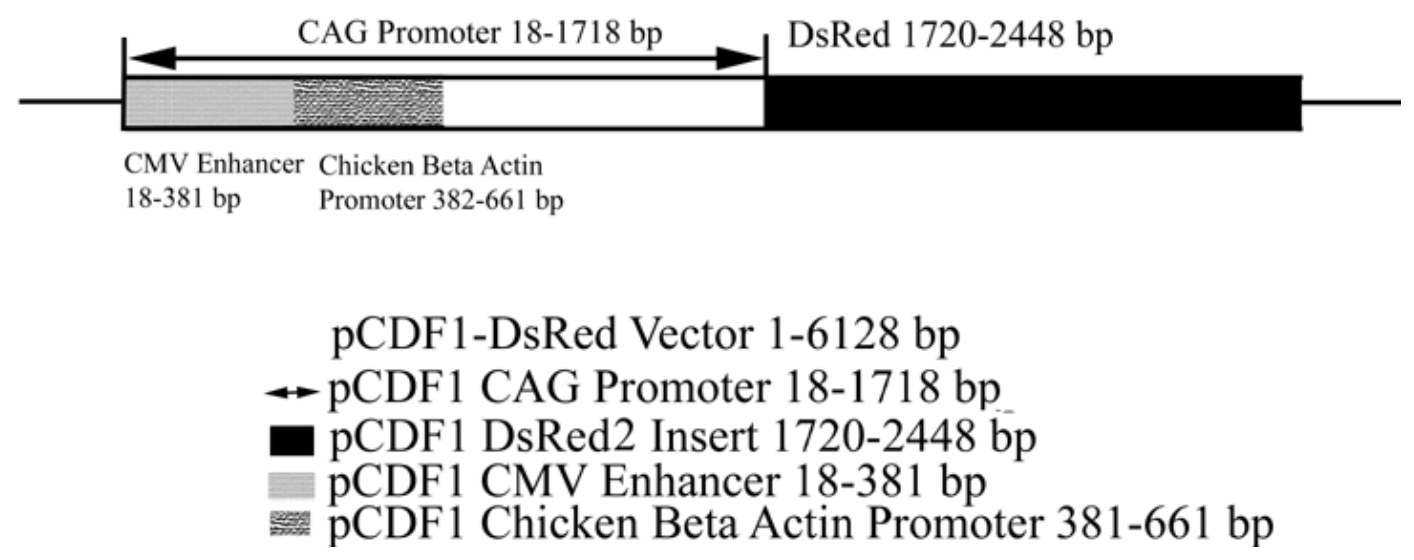

Figure 1. Schematic representation of the lentiviral construct. The illustrated construct was cloned into pCDF- (Systems Biosciences (Mountain View CA). DsRed 2 is driven by the CAG promoter which consists of a cytomegalovirus (CMV) enhancer, and the chicken beta-actin promoter driving DsRed2 expression-

Table 1. Hatchability of injected (INJ) and intact control geckos (CNTL).

\begin{tabular}{lccc}
\hline Parameter & Viable offspring & Total embryos & \% Hatchability \\
\hline INJ gecko embryos & 41 & 112 & 36.6 \\
CNTL gecko embryos & 14 & 20 & 70 \\
Total gecko embryos & 55 & 132 & 41.6 \\
\hline
\end{tabular}

examination. Bands indicative of positive results were excised from the gels and purified using a Qiagen Gel Purification kit (Valencia, CA). Wild-type negative control DNA and water-only samples were included with every PCR reaction run to ensure that there was no cross-contamination among samples.

Subsequently, the DNA was reamplified using DsRed 2 primers to amplify a nested $169 \mathrm{bp}$ segment internal to the $711 \mathrm{bp}$ fragment. Specifically, the bands were excised from the agarose gels, and purified using a Qiagen Gel Purification kit (Valencia, CA), and the fragments were cloned into the pGEM-T easy (Promega, Madison WI) vector. Subsequently, the inserts were sequenced using both the SP6 and the T7 primer sets. (Eton BioScience, Durham, NC). All 169 bp were homologous to Ds Red2.

\section{Histological evaluation}

Anterior half of gecko samples were placed in an $80 \%$ PBS, $20 \%$ sucrose solution. Samples were stored over night at $4^{\circ} \mathrm{C}$. A 2:1 solution of $20 \%$ sucrose OCT media was prepared as an embedding medium (Tissue-Tek, Torrence CA). Gecko bodies were placed into dry embedding molds, which were filled with embedding medium. The mold was placed in a small container of methyl butane and floated over liquid nitrogen until the embedding media solidified.

Ten micron thick sections were placed on glass slides and mounted in a glycerol based media containing $1 \mathrm{mg} / \mathrm{mL} \mathrm{p}$ phenylenediamine (Swartz et al., 1990). Coverslips were sealed with clear nail polish. A Leica DMR® microscope (Leica Microsystems, Bannockburn, IL, USA) with epifluorescence illumination and Differential Interference Contrast (DIC) optics was used to observe the tissue sections.

\section{RESULTS}

\section{Hatchability and incubation}

Hatchability of the injected geckos was $36.6 \%$ versus $70 \%$ in the CNTL group (Table 1).

\section{Visual screening}

25 Hatched INJ geckos were observed under fluorescent illumination using the Nightsea Flashlight. Geckos exhibited mosaic of visual fluorescence. All exhibited DsRed 2 fluorescence (Figure 2).

Qualitatively, the diges-tive system routinely exhibited DS Red 2 Fluorescence, and punctuate fluorescence was observed in the skin of the geckos. DsRed fluorescence was never observed in the skin or the organs of any CNTL geckos (Figure 2).

\section{PCR screening}

DNA samples were amplified using primers that would be expected to generate a $711 \mathrm{bp}$ fragment (Figure 3A). Subsequently, the 711 bp band was amplified using PCR 


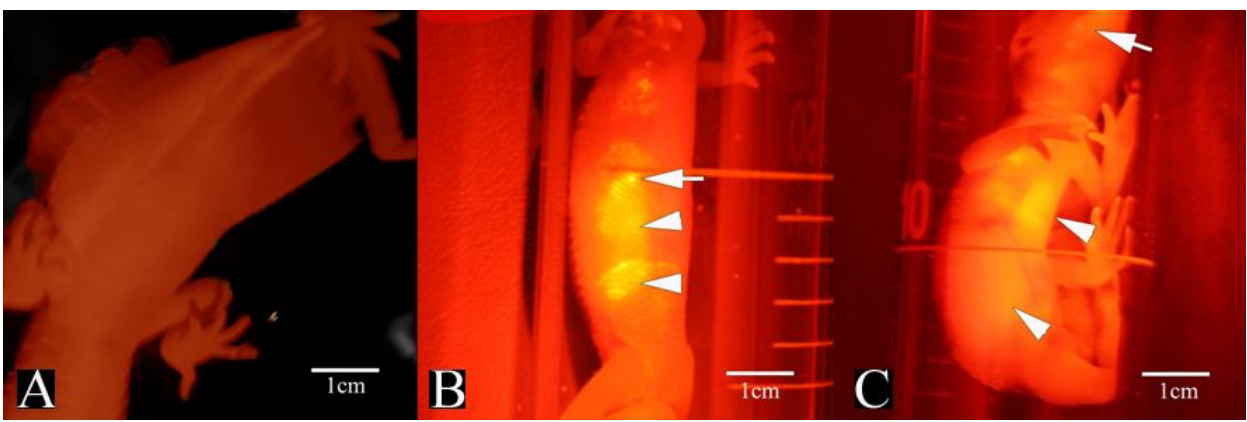

Figure 2. Wild-type Control (CNTL; A) and Injected (INJ; B, C) gecko hatchlings viewed under fluorescent illumination.Arrow heads indicate organ fluorescence; arrows indicate punctate fluorescence spots in skin. Scale bar is $1 \mathrm{~cm}$.

A

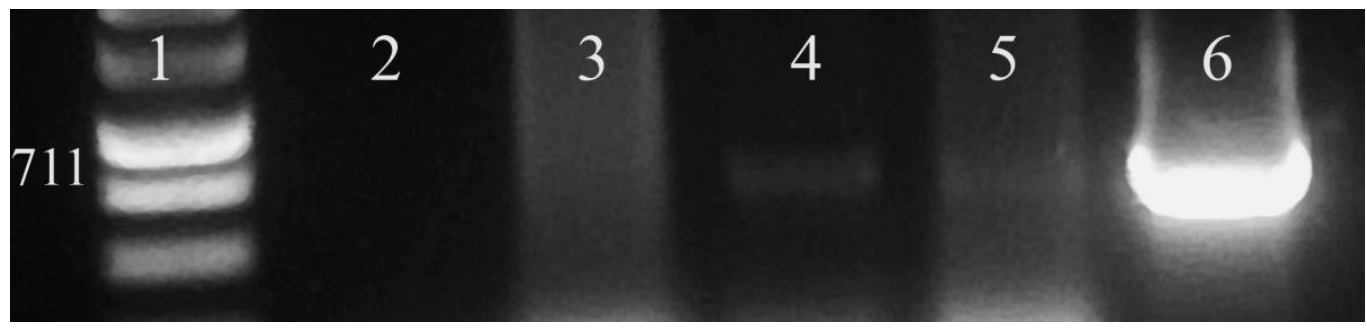

Figure 3A. 711 Amplification products From DsRed primers and DNA from intact (CNTL) and injected gecko embryos (INJ) DNA. Lane 1, 1kb ladder; Lane 2, H2O control; Lane 3, CNTL gecko DNA; Lane 4, INJ gecko embryo 1; Lane 5, INJ gecko embryo 2; Lane 6, positive control DNA from DsRed 2 transfected 3 T 3 cells.

primers internal to the 711 band (Figure 3B). Injected gecko DNA was tested for presence of the DsRed 2 gene using 711 primers. Out of the INJ population, 9 samples of DNA were randomly selected for PCR testing. Out of the nine tested, eight were found to be positive using nested PCR. An $89 \%$ overall success rate for success of the presence of the gene was achieved.

\section{Microscopy}

Tissue sections were examined for DsRed fluorescence under a Texas Red filter using a 40x objective (Figure 4) and a 20x objective (Figures 5, 6 and 7). Tissues observed to be positive for DsRed expression were muscle, kidney, heart, and brain.

\section{DISCUSSION}

A single injection of retroviral particles carrying the lacZ gene to chicken eggs was an efficient method of transgenesis; producing more transgenic chickens than using multiple viral injections (Mozdziak et al., 2003). The difference in hatchability between INJ and CNTL geckos may be explained by the injection procedure. Insertion of viral particles into an embryo has been shown to lower hatchability. When similar procedures were performed on chicken embryos, fully intact eggs had $67.9 \%$ hatchability, and eggs where a small injection hole was made, hatchability was $56.8 \%$ (Bednarczyk et al., 2000). When injecting concentrated retroviral particles into freshly laid chicken egg, the hatchability dropped to below $30 \%$ (Harvey et al., 2002). The hole in the shell also opens the embryo to a greater possibility of infection from mold and bacteria, and makes the embryo more subject to temperature and humidity fluctuates. Embryos can also be damaged physically from a piercing from the needle causing malformations. The success of lentiviral transgenesis is reliant on the high titer of virus, and availability of the virus to the embryo (Gama Sosa et al., 2010).

It is likely that only a single insertional event occurred by employing the lentiviral vector (Mozdziak et al., 2006). 


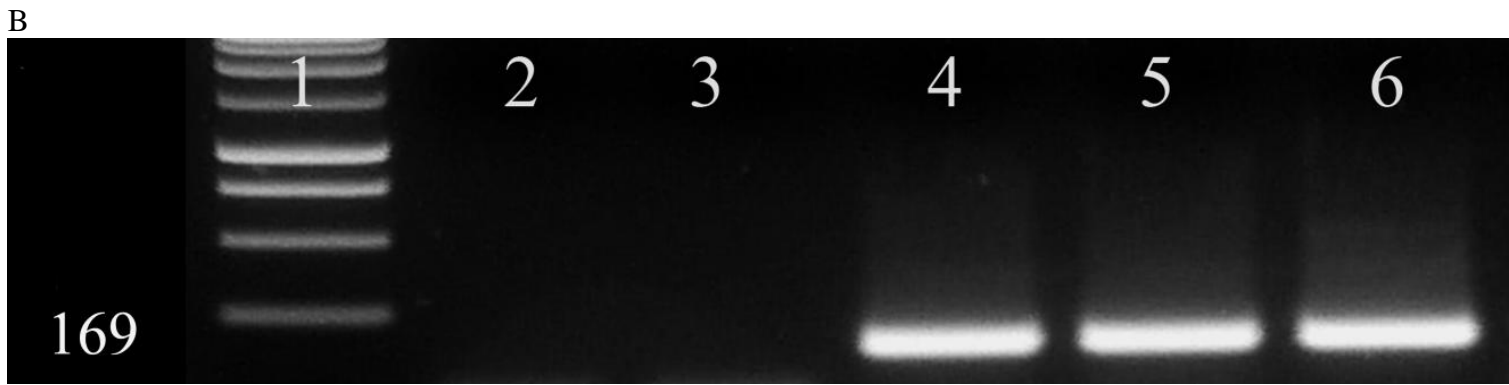

Figure 3B. 169 Amplification of injected and intact gecko DNA from excised 711 gel bands. Lane 1, 1kb ladder; Lane 2, H2O control; Lane 3, Intact gecko DNA; Lane 4, Injected gecko I; Lane 5, Injected gecko 2; Lane 6, Positive control DNA from DsRed 2 infected 3 T3 cells.

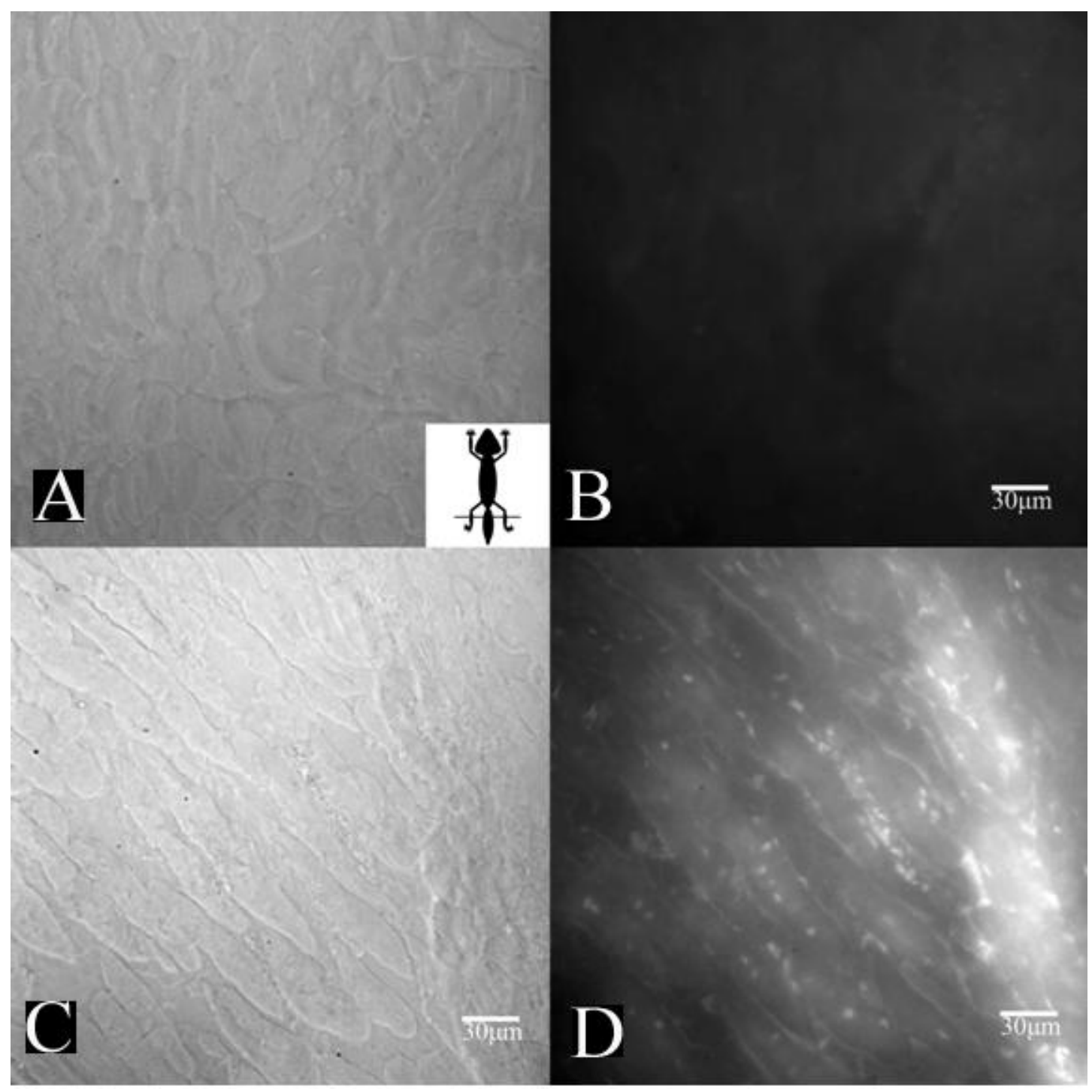

Figure 4. $C N T L(A, B)$ and $I N J(B, D)$ gecko muscle viewed with direct light/DIC optics $(A, C)$ and fluorescence illumination through a Texas Red filter set (B, D). Schematic in panel A illustrates plane/orientation of section. Images represent skeletal muscle from the tail. Scale bar is $30 \mu \mathrm{m}$. 


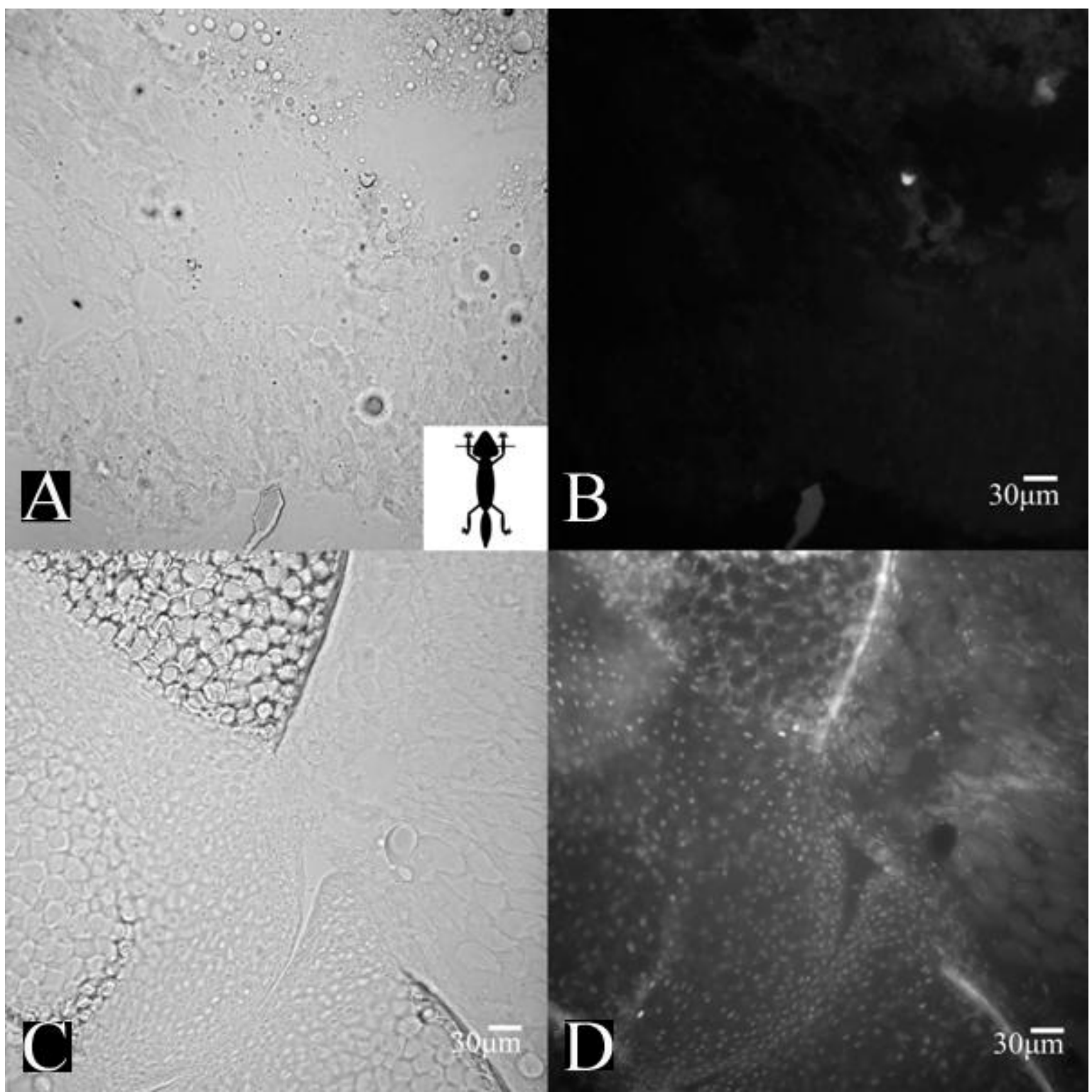

Figure 5. CNTL (A, B) and INJ (C, D) gecko cranial tissue viewed under direct light/DIC optics (A, C) and fluorescence illumination through aTexas Red (B, D) filter set. Schematic in panel A illustrates plane/orientation of section. Scale bar is $30 \mu \mathrm{m}$.

PCR analysis was chosen over Southern analysis because PCR is a more sensitive methodology. Specifically, a successful Southern blot requires approximately $20 \mu \mathrm{g}$ of DNA to generate a detectable signal whereas a PCR reaction requires less than a single microgram (Echelard, 1997; Mozdziak et al., 2006)

The DsRed 2 gene was driven by the CAGpromoter (Figure 1), which results in protein production in the skin, liver, brain, heart, kidney, spleen and lung tissues (Lois et al., 2002; Fahim et al., 2009). The digestive organs routinely exhibited DS Red fluorescence, while negative control wild-type geckos did not exhibit any signal (Figure 2), which correlates with other transgenic studies suggesting that lentiviral transgenesis results in robust digestive system expression (McGrew et al., 2004). Punctate staining was observed at variable locations on the skin of hatched geckos, but was never observed in the skin of negative control geckos. Mosaic gene expression and insertion is expected in the G0 founder animals (Mozdziak and Petitte, 2004) making the observation unsurprising that the first round of PCR 


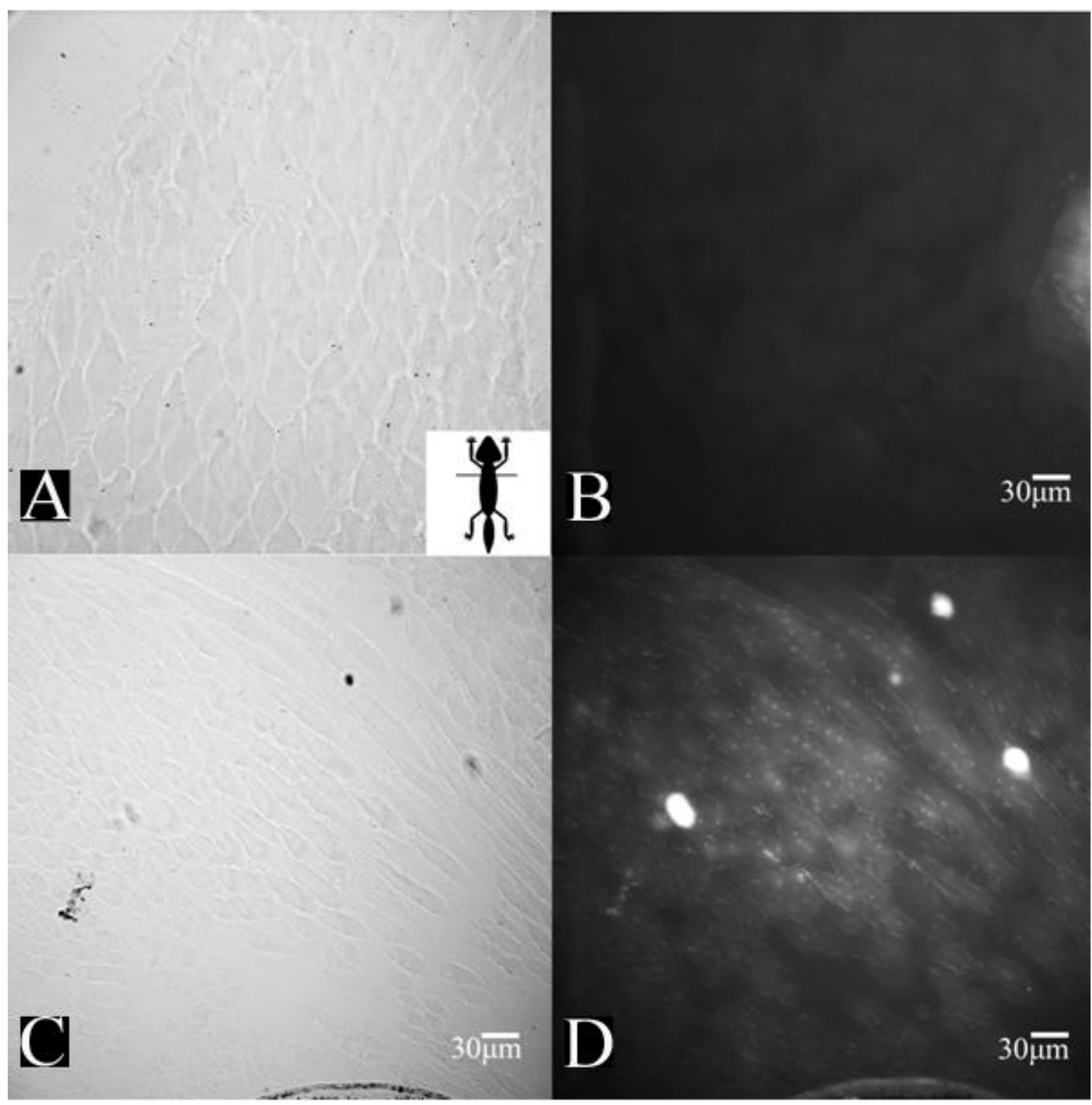

Figure 6. $\operatorname{CNTL}(A, B)$ and INJ (C, D) gecko cardiac muscle viewed under direct light/DIC optics $(A, C)$ and fluorescence illumination through aTexas Red (B, D) filter set. Schematic in panel A illustrates plane/orientation of section. Image represents cardiac tissue. Scale bar is $30 \mu \mathrm{m}$.

amplification was not robust. In G0 animals, the lentiviral construct does not likely infect every cell in the embryo. However, the second round of PCR amplification with internal primers further substantiated the initial amplification results; and PCR fragments were confirmed via DNA sequencing. All amplification procedures were repeated three separate times, and great care was taken to ensure that there was no cross-contamination in any of the reactions before a positive result was accepted. Furthermore, the PCR results were correlated with the visual expression results suggesting DsRed 2 gene transfer to the embryos through lentiviral transgenesis.

DsRed transgenic proteins were observed in muscle, heart, kidney, liver, and brain. The distribution of DsRed expression is similar to studies of GFP lentiviral transgenic mice, where the expression of transgenic proteins was found in all tissues and organs analyzed including, skin, bone, muscle, lung, liver, stomach, intestine, kidney, brain, retina and gonads (Lois et al., 2002; Wiznerowicz and Trono, 2005). Punctate staining 


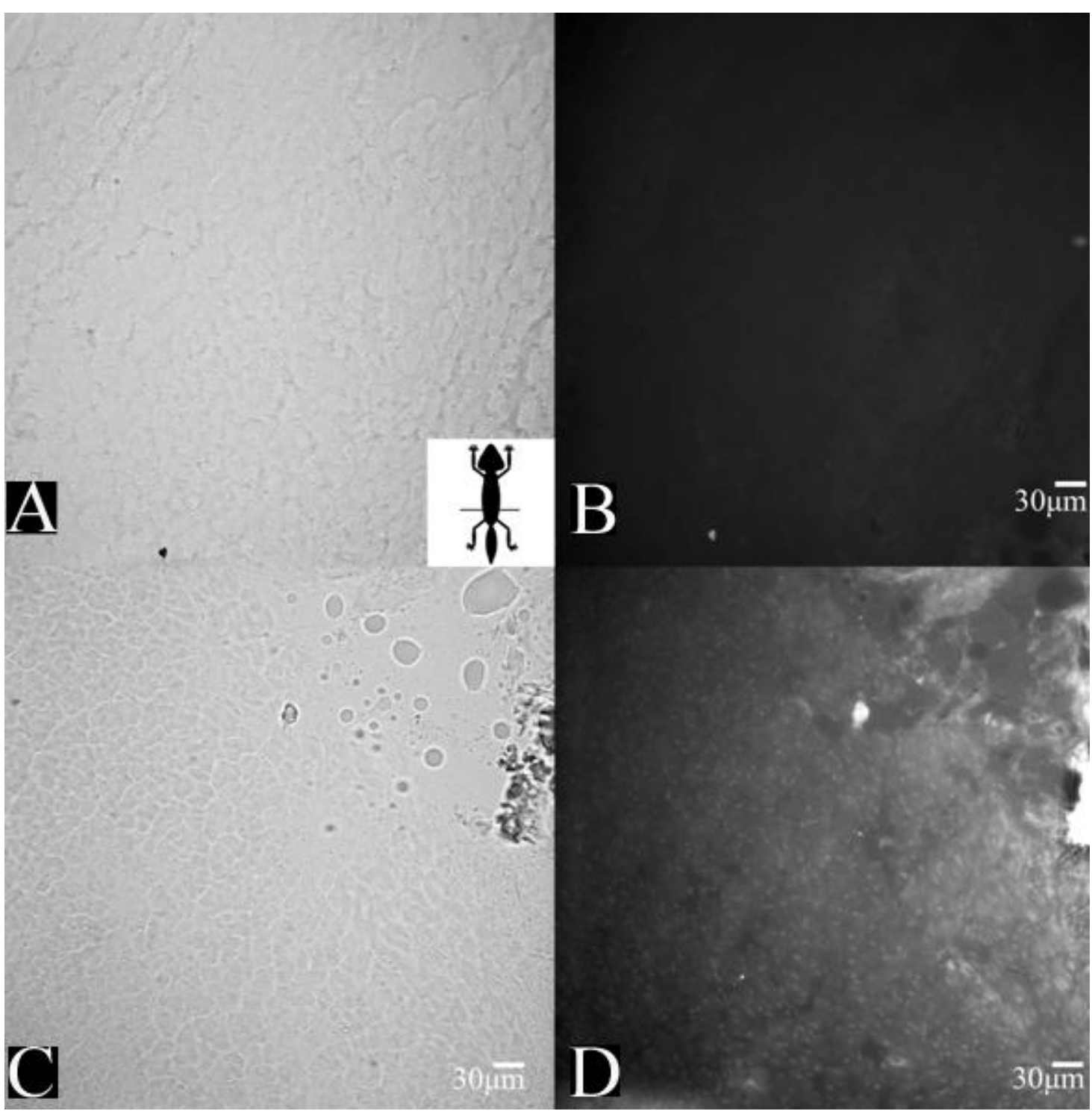

Figure 7. CNTL (A, B) and INJ (C, D) gecko kidney tissue viewed under direct light/DIC optics (A, C) and fluorescence illumination through aTexas Red (B, D) filter set. Schematic in panel $A$ illustrates plane/orientation of section. Image represents kidney tissue. Scale bar is $30 \mu \mathrm{m}$.

was observed in tissue sections, which may result from DsRed protein aggregation. For the purposes of showing proof of concept to generate transgenic geckos, punctuate staining was not problematic. Lentiviral transgenesis is a forthcoming method of creating transgenic lines. Expressing transgenic F1 progeny have been produced in mice using a similar method of lentiviral transduction (Nakanishi et al., 2002; Lois et al., 2002). Leopard geckos reach breeding age after approximately 2 years, or when they reach $40 \mathrm{~g}$ (de Vosjoli et al., 2005). Although germline transmission to the F1 generation was beyond the scope of the current study because of the long interval between generations, it is possible that successful germline transmission will occur, based upon the success in other species (Marsh-Armstrong et al., 1999; Lois et al., 2002). The present study is the first to demonstrate that lentiviral vectors can insert DNA into the genome of reptiles, and transgenic protein can be expressed. Little is known about the gene function, cell signaling, growth and development of reptiles compared to other species. The methods reported in this manuscript may lead to studies of promoter function, small interfering RNA knockdown of protein expression, and gene function to unlock the mechanisms governing reptile biology. 
Furthermore, transgenic reptiles carrying reporter genes are useful tools for developmental biologists because the cells can be used to study the mechanisms of cell migration, differentiation, and cell fate in the same way that transgenic chickens can be employed to learn about avian development (Mozdziak and Petitte, 2004). The present results will unlock a new range of technology that can be employed to further understand the reptilian system.

\section{REFERENCES}

Bednarczyk M, Lakota P, Siwek M (2000). Improvement of hatchability of chicken eggs injected by blastoderm cells. Poult. Sci. 79:18231828.

Borwornpinyo S, Brake J, Mozdziak PE, Petitte JN (2005). Culture of chicken embryos in surrogate eggshells. Poultry Sci., 84:1477-1482.

Bull JJ (1987). Temperature-sensitive periods of sex determination in a lizard similarities with turtles and crocodilians. J. Exp. Zoo. 241:143148.

Carvan MJ, Dalton TP, Stuart GW, Nebert DW (2000). Transgenic zebrafish as sentinels for aquatic pollution. Annals of the New York Academy of Sciences 919:133-147.

Chudakov DM, Matz MV, Lukyanov SA (2010). Fluorescent proteins and their applications in imaging living cells and tissues. Am. Physiol. Soc. 90:1103-1163.

Cockrell AS, Kafri T (2007). Gene delivery by lentivirus vectors. Mole. Biotechnol. 36:184-204.

Curran MA, Ochoa MS, Molano RD, Pileggi A, Inverardi L, Kenyon NS,

Nolan GP, Ricordi C, Fenjves ES (2002). Efficient transduction of pancreatic islets by feline immunodeficiency virus vectors. Transplantation 74:299-306.

Curran MA, Nolan GP (2002). Nonprimate lentiviral vectors. Current Topics in Microbiol. Immunol. 261:75-105.

de Vosjoli P, Tremper R, Klingenberg R (2005). The herpetoculture of leopard geckos: twenty seven generations of living art. Advanced Visions Inc. USA.

Deheyn DD, Kubokawa K, McCarthy JK, Murakami A, Porrachia M, Rouse GW, Holland ND (2007). Endogenous green fluorescent protein (GFP) in amphioxus. Biological Bulletin, 213:95-100.

Derksen TA, Sauter SL, Davidson BL(2002). Feline immunodeficiency virus vectors. Gene transfer to mouse retina following intravitreal injection. J. Gene Med. 4:463-469.

Echelard Y (1997). Genetic Mosacism in the generation of Transgenic Mice. in (L. Houdebine) Transgenic Animals Generation and Use . Harwood Academic Publishers

Fahim AT, Wang H, Feng J, Ginsburg D (2009). Transgenic overexpression of a stable plasminogen activator inhibitor-1 variant. Thrombosis Research 123:785-792.

Fini JB;Pallud-Mothre S, Le Mevel S, Palmier K, Havens CM, Le Brun M, Mataix V, Lemkine GF, Demeneix BA, Turque N, Johnson PE (2009). An innovative continuous flow system for monitoring heavy metal pollution in water using transgenic Xenopus laevis tadpoles. Environ. Sci. Technol. 43: 8895-8900.

Gama Sosa MA, Gasperi RD, Elder GA (2010). Animal transgenesis: an overview. Brain Structure and Function 214:91-109.

Gong, ZBJ, Wan H, (2001). Green fluorescent protein (GFP) transgenic fish and their applications. Genetica 111:213-225.

Haddock SHD, Case JF (1999). Bioluminescent spectra of shallow and deep-sea gelatinous zooplankton: ctenophores, medusae and siphonophores, Marine Biol. 133:571-582.

Harvey AJ, Speksnijder G, Baugh LR, Morris JA, Ivarie R (2002). Consistent production of transgenic chickens using replicationdeficient retroviral vectors and high-throughput screening procedures. Poultry Science 81:202-212.

Loewen N, Fautsch MP, Peretz M, Bahler CK, Cameron JD, Johnson $\mathrm{DH}$, Poeschla EM (2001). Genetic modification of human trabecular meshwork with lentiviral vectors, Human Gene Therapy 12:2109 2119.

Lois C, Hong EJ, Pease S, Brown EJ, Baltimore D (2002). Germline transmission and tissue-specific expression of transgenes delivered by lentiviral vectors. Science: $295: 868-872$.

Marsh-Armstrong N, Huang H, Berry DL, Brown DD (1999). Germ-line transmission of transgenes in Xenopus laevis PNAS 96:1438914393.

Matz MV, Fradkov AF, Labas YA, Savitsky AP, Zaraisky AG, Markelov ML, Lukyanov SA (1999). Fluorescent proteins from nonbioluminescent Anthozoa species, Nat. Biotechnol. 17: 969-973

McGrew MJ, Sherman A, Ellard FM, Lillico SG, Gilhooley HJ, Kingsman AJ, Mitrophanous KA, Sang H (2004). Efficient production of germline transgenic chickens using lentiviral vectors. EMBO 5: 728-733.

Mozdziak PE, Borwornpinyo S, McCoy DW, Petitte JN (2003). Development of transgenic chickens expressing bacterial $\beta$ galactosidase. Dev. Dyn. 226:439-445.

Mozdziak PE, Petitte JN (2004).- Status of transgenic chicken models for developmental biology. Dev. Dyn. 229:414-421.

Mozdziak PE, Wu Q, Bradford JM, Pardue SL, Borwornpinyo S, Giamario C, Petitte JN (2006). Identification of the lacZ insertion site and beta-galactosidase expression in transgenic chickens. Cell Tiss. Res. 324:41-53.

Mozdziak PE, Petitte JN (2010). Transgenic snakes and methods of making. US Patent 7,663,019. Washington DC.

Nakagawa N, Hoogenraad CC (2011). Lentiviral Transgenesis. Methods Mol. Biol. 693:117-142.

Nakanishi T, Kuroiwa A, Yamada S, Isotani A, Yamashita A, Tairaka A, Hayashi T, Takagi T, Ikawa M, Matsuda Y, Okabe M (2002). FISH analysis of 142 EGFP transgene integration sites into the mouse genome. Genomics 80:564-574.

Pfeifer A (2004). Lentiviral Transgenesis. Transgenic Res. 13: 513-522.

Price MA, Case SS, Carbonaro DA, Yu XJ, Petersen D, Sabo KM, Curran MA, Engel BC, Margarian H, Abkowitz JL, Nolan GP, Kohn DB, and Crooks GM (2002). Expression from second-generation feline immunodeficiency virus vectors is impaired in human hematopoietic cells. Mol. Ther. 6:645-652.

Sakaue-Sawano A, Kurokawa H, Morimura T, A. Hanyu, H. Hama, H. Osawa, S. Kashiwagi, K. Fukami, T. Miyata, H. Miyoshi, T. Imamura, M. Ogawa, H. Masai, and A. Miyawaki. (2008). Visualizing spatiotemporal dynamics of multicellular cell-cycle progression. Cell 132:487-498.

Shagin DA, Barsova EV, Yanushevich YG, Fradkov AF, Lukyanov KA, Labas YA, Semenova TN, Ugalde JA, Meyers A, Nunez JM, Widder EA, Lukyanov SA, Matz MV (2004). GFP-like proteins as ubiquitous metazoan superfamily: evolution of functional features and structural complexity. Mole. Biol. Evol. 21:841-850.

Stein CS, Davidson BL (2002). Gene transfer to the brain using feline immunodeficiency virus-based lentivirus vectors. Methods Enzymol. 346:433-454

Strack RL, Strongin DE, Mets L, Glick BS, Keenan RJ (2010). Chromophore formation in DsRed occurs by a branched pathway. JACS Articles, 132:8496-8505.

Swartz DR, Greaser ML, Marsh BB (1990). Regulation of binding of subfragment 1 in isolated rigor myofibrils. J. Cell Biol. 111:2989-3001.

Thorogood J, Whimster IW (1979). The maintenance and breeding of the leopard gecko as a laboratory animal, International zoo yearbook, 19:74-79.

Valleley EMA, Cartwright EJ, Croft NJ, Markham AF, Coletta PL (2001). Characterization and expression of Sox9 in the leopard gecko, Eublepharis macularius. J. Exp. Zool. 291: 85-91.

Wang G, Slepushkin V, Zabner J, Keshavjee S, Johnston JC, Sauter SL, Jolly DJ, Dubensky TW, Davidson BL, McCray PB (1999). Feline immunodeficiency virus vectors persistently transduce nondividing airway epithelia and correct the cystic fibrosis defect. J. Clin. Investigat. 104:R55-62.

Whimster IW (1978). Nerve supply as a stimulator of the growth of tissues including skin. II, Animal evidence. Clin. Exp. Dermatol. 3:389-410. 
Wise PAD (1997). Leopard geckos. Reptile Life, 1:24-27.

Wise PAD, Vickaryous MK, Russel AP (2009). An embryonic staging table for in ovo development of Eublepharis macularius, the leopard gecko. Anatomical Rec. 292:1198-1212.

Wiznerowicz M, Trono D (2005). Harnessing HIV for therapy, basic research and biotechnology. Trends in Biotechnol. 23:42-47.
Yanushevich YG, Staroverov DB, Savitsky AP, Fradkov AF, Gurskaya NG, Bulina ME, Lukyanov KA, Lukyanov, SA (2002). A strategy for the generation of non-aggregating mutants of Anthozoa fluorescent proteins. FEBS Lett. 511:11-14. 